\title{
Gestão democrática e participação na decisão nas escolas: análise das legislações das redes municipais do estado do Rio de Janeiro
}

\author{
Karine Vichiett Morgan \\ Daniela Patti do Amaral
}

\section{Resumo}

A gestão democrática é um princípio da educação pública, inscrita na meta 19 do Plano Nacional de Educação (PNE 2014-2024). Na perspectiva de pensar uma escola com vivências democráticas, os colegiados de participação e decisão constituem espaços para a materialização dessas vivências em busca de uma educação de qualidade. Para compreender o cenário das instâncias de colegialidade nas escolas, buscaram-se legislações que regulamentaram a gestão democrática nos 92 municípios do estado do Rio de Janeiro, instituídas após 2014. Localizadas 40 legislações, foram selecionadas 12 para análise, de modo a investigar como se configuram conselhos escolares, grêmios estudantis e associações de apoio à escola. Os resultados iniciais indicam movimentos fragmentados para regulamentação da gestão democrática, além da necessidade de aprofundamento empírico e teórico para a compreensão das instâncias de colegialidade e participação da comunidade escolar com vistas a uma educação de qualidade.

Palavras-chave: qualidade; gestão democrática; colegialidade na escola. 


\section{Abstract \\ Democratic management and participation in the decision-making in school: an analysis of the legal documents of the municipal school systems in the State of Rio de Janeiro}

School democratic management is a principle of public education, inscribed at the National Education Plan in its 19th goal (PNE 2014-2024). With the intent of reflecting about schools promoting democratic experiences, participation and decision collegialities are spaces in which these experiences are actualized in search of quality education. Aiming to understand the scenario of collegiality instances in schools, it was used the legislation that regulates democratic management in 92 municipalities of the State of Rio de Janeiro, from 2014 onwards. Of the 40 legislations found, 12 were selected for analysis, in order to investigate how school councils, student unions, and school support associations are configured. Initial results indicate fragmented movements seeking the regulation of democratic management, in addition to the need for empirical and theoretical deepening to further understand the instances of collegiality and participation of the school community for a quality education.

Keywords: democratic management; quality; school collegiality.

\section{Resumen \\ Gestión democrática y participación en la toma de decisiones en las escuelas: análisis de la legislación de las redes municipales en el estado de Río de Janeiro}

La gestión democrática de la escuela es un principio de la educación pública, inscrita en la meta 19 del Plan Nacional de Educación (PNE 2014-2024). En la perspectiva de pensar una escuela con vivencias democráticas, los colegiados de participación y decisión constituyen espacios para la materialización de estas vivencias en busca de una educación de calidad. Para comprender el escenario de las instancias de colegialidad en las escuelas, se buscaron legislaciones que regularon la gestión democrática en los 92 municipios del estado de Río de Janeiro, instituidas después del 2014. Encontradas 40 legislaciones, fueron seleccionadas 12 para análisis a fin de investigar cómo se configuran consejos escolares, centros estudiantiles y asociaciones de apoyo a la escuela. Los resultados iniciales indican movimientos fragmentados para la regulación de la gestión democrática, además de la necesidad de profundización empírica y teórica para comprender las instancias de colegialidad y participación de la comunidad escolar para una educación de calidad.

Palabras clave: calidad; gestión democrática; colegialidad en la escuela. 


\section{Introdução}

A gestão democrática das escolas públicas é um princípio apresentado na Constituição Federal de 1988 e na Lei de Diretrizes e Bases da Educação Nacional (LDB - Brasil. Lei $n^{\circ}$ 9.394, 1996). Este princípio constitucional é novamente introduzido como tema específico de uma das 20 metas do Plano Nacional de Educação (PNE) para o decênio 2014-2024 (Brasil. Lei no 13.005, 2014). A meta 19, que trata da gestão democrática, propõe assegurar condições para a efetivação da gestão democrática da educação, associada a critérios técnicos de mérito e desempenho e à consulta pública à comunidade escolar. Para o alcance da meta, apresenta oito estratégias que contemplam o processo de seleção de diretores, a constituição de espaços de colegialidade, participação e deliberação nas escolas, dentre outros aspectos. A concepção de escola democrática como processo está articulada à participação política dos coletivos no cotidiano da instituição escolar.

Arelaro, Jacomini e Carneiro (2016) argumentam que a redação dada pela LDB ao tema da gestão democrática frustrou aqueles que esperavam detalhamento acerca da efetivação de procedimentos concretos nos sistemas de ensino. Conforme os autores, ao estabelecer apenas os princípios gerais, a LDB deixou para cada sistema de ensino definir a forma de provimento do diretor de escola, os conselhos que seriam instituídos, a proporção de participação de cada segmento da comunidade escolar, bem como o caráter deliberativo ou consultivo desses blocos.

Como afirmado por Souza (2009, p. 126), a gestão democrática é um processo que "tem como base a participação efetiva de todos os segmentos da comunidade escolar, o respeito às normas coletivamente construídas para os processos de tomada de decisões e, ainda, a garantia de amplo acesso às informações aos sujeitos da escola". Na perspectiva de pensar uma escola com vivências democráticas, consideramos que os colegiados de participação e decisão - conselhos escolares, grêmios estudantis e associações de pais e mestres - se constituem como espaços para a materialização dessas vivências em busca de uma educação de qualidade.

De modo a compreender como os colegiados nas escolas têm sido pautados pelos legisladores municipais no âmbito do estado do Rio de Janeiro, realizamos, ao longo do ano de 2019, uma busca por leis que regulamentam a gestão democrática, publicadas a partir de 2014

\section{O debate contemporâneo sobre qualidade da educação}

O termo qualidade, quando relacionado à educação, não traz em si um sentido único. Ao contrário, os múltiplos significados que pode assumir são tão numerosos quanto as questões de fundo em que são ancorados. Tal construção semântica carrega no significado da expressão "educação de qualidade" questões mais abrangentes do tecido social - notadamente concepções de homem, de mundo e de educação -, permanentemente em disputa na sociedade.

Desde as declarações dos organismos internacionais até as conversas de bar, passando pelas manifestações das autoridades educacionais, as organizações 
de professores, as centrais sindicais, as associações de pais, as organizações de alunos, os porta-vozes do empresariado e uma boa parte dos especialistas, todos coincidem em aceitar a qualidade da educação ou do ensino como o objetivo prioritário ou como um dos muito poucos que merecem consideração. (Enguita, 2015, p. 95).

No Brasil, as discussões foram marcadas historicamente por três significados distintos que ainda transitam na sociedade de maneira concreta e simbolicamente, como afirmam Oliveira e Araújo (2005, p. 8):

\begin{abstract}
[...] um primeiro, condicionado pela oferta limitada de oportunidades de escolarização; um segundo, relacionado à ideia de fluxo, definido como número de alunos que progridem ou não dentro de determinado sistema de ensino; e, finalmente, a ideia de qualidade associada à aferição de desempenho mediante testes em larga escala.
\end{abstract}

O primeiro significado está relacionado à expansão do ensino no período de 1930 a 1970. Com a Revolução de 1930, há um movimento que reivindica o acesso das massas à educação e encontra eco no governo populista de Getúlio Vargas. Embora a educação tenha permanecido altamente elitista (e sem ignorar as contradições do processo de expansão), "não se pode negar que esse momento representou uma conquista social, já que foi viabilizada a escolarização às classes populares" (Castro, 2009, p. 24). Tal processo foi nomeado por Beisiegel (2006, p. 116) de "democratização do ensino".

As preocupações acerca da qualidade da educação e sua inserção nas discussões sobre educação têm início com a expansão das "oportunidades de escolarização da população" (Hobsbawm, 1995, apud Oliveira; Araújo, 2005, p. 8) e com uma mudança significativa do perfil dos alunos que tinham acesso à escola a partir dos anos de 1940. Para Oliveira e Araújo (2005), a simbiose entre o que se considerava qualidade em educação e as escolas elitizadas foi paulatinamente desconstruída com a democratização do acesso dos mais vulneráveis aos bancos da escola. Os autores apontam que a representação da escola de qualidade pelo senso comum era (e permanece sendo) decorrente dos rigorosos fatores de exclusão intra e extraescolares, ou seja, a escola socialmente vista como escola de qualidade excluía sistematicamente os estudantes que dela mais precisavam.

Nos anos finais da década de 1980 e primeira metade da década de 1990, houve um segundo momento de expansão das matrículas de meninos e meninas no Brasil, em especial pela elevação do status da educação a direito público subjetivo, garantido constitucionalmente a partir de 1988. A taxa bruta de atendimento à faixa etária de 7 a 14 anos de idade, que correspondia (em uma trajetória escolar sem retenções) ao ensino fundamental obrigatório à época, no período de 1980 até 1994, teve um incremento de mais de 15\%, alcançando 96,2\% das crianças matriculadas nas escolas do País. Na faixa etária de 4 a 6 anos de idade, a expansão foi ainda mais consistente, com quase 20\% de crescimento no mesmo período (Estatísticas..., 1996).

Najjar (2015) nomeia a expansão do acesso à escolarização como "invasões bárbaras". Os bárbaros, para o Império Romano, eram os incivilizados, aqueles que não eram romanos, os outros que não eles próprios. Em analogia, Najjar refere-se 
aos bárbaros na escola, que representam os não familiares, os estranhos à natureza da escola, e que, em última instância, a ela não pertencem.

Foram tomadas medidas de ordem infraestrutural, que viabilizaram a incorporação de tal contingente: construção de prédios, oferecimento de vagas, contratação de pessoal. Entretanto, do ponto de vista pedagógico e institucional, poucas alterações foram propostas para atender aos "bárbaros". A escola entrava em crise diante da discrepância entre estes e o aluno por ela idealizado. Estava claro que apenas o alargamento do acesso não trazia qualidade à educação.

Essa constatação leva ao segundo significado do conceito de qualidade em educação: a ênfase na permanência dos alunos na escola, na ampliação do tempo de estudo, na diminuição dos índices de repetência e evasão (Castro, 2009).

Acompanhando a evolução das matrículas, houve também uma queda nos níveis de retenção e evasão e uma ascensão no percentual de promoção dos estudantes. Em 1984, 45\% dos alunos matriculados no ensino fundamental eram retidos ou abandonavam a escola. Se levarmos em conta apenas o $1^{\circ}$ ano de escolaridade, a situação era ainda mais dramática, contando com $44 \%$ de alunos retidos e $5 \%$ de evasão, ou seja, quase metade dos alunos matriculados no $1^{\circ}$ ano do ensino fundamental fracassava. Tais indicadores tiveram substancial melhora ao longo dos anos e chegam ao início dos anos de 1990 contando a aprovação, a retenção e o abandono com percentuais de 62\%, 33\% e 5\%, respectivamente (Brasil. Inep, 2003). Atualmente, se levarmos em conta apenas o primeiro ano, em 2019, o índice de aprovação foi de 98\%; de reprovação, 1,2\%; e o de abandono, 0,8\%. Para todo o ensino fundamental, alcançamos 91\% de aprovação, 7,4\% de reprovação e apenas $1,6 \%$ de abandono.

Entretanto, embora vejamos uma franca evolução nos números que, ao menos teoricamente, afeririam a qualidade da educação, o problema persiste. Mais uma vez, percebe-se que a diminuição dos números de evadidos e repetentes também não se converteu em uma escola de qualidade. A escola, agora com os "bárbaros" em seu interior e progredindo na trajetória escolar, permanece em crise.

Ainda no fim dos anos de 1980, inicia-se a circulação do terceiro significado apontado por Oliveira e Araújo (2005) e por Castro (2009), que completa o quadro conceitual que aqui analisamos. Tal significado, que ganha fôlego com a introdução de políticas neoliberais no Brasil nos anos de 1990, relaciona a qualidade da educação ao desempenho dos estudantes.

A crise educacional no discurso propagado pelo ideário neoliberal não poderia ser relacionada à necessidade de ampliação do atendimento cujas taxas, como visto, cresciam aceleradamente em direção à universalização. Sob a égide neoliberal, a crise educacional era discursivamente apresentada (e permanece sendo) como fruto da expansão do atendimento, desacompanhada de critérios de eficácia, eficiência e produtividade das instituições escolares e dos sistemas de ensino. A crise na educação, sob essa ótica, estaria ligada ao gerenciamento do Estado (Gentili, 1996). Nessa perspectiva, convencia-se a população de que à educação não faltava investimento, pois havia vagas. Gentili (1996), em crítica a tal ideário, identifica que, de acordo com o discurso neoliberal, era necessária a aplicação mais inteligente 
e eficaz dos recursos existentes, além de instrumentos capazes de diagnosticar e dispositivos para corrigir a incompetência:

No campo educativo, o discurso da qualidade foi assumindo a fisionomia de uma nova retórica conservadora funcional e coerente com o feroz ataque que hoje sofrem os espaços públicos (democráticos ou potencialmente democráticos), entre eles, a escola das maiorias. (Gentili, 2015, p. 115).

O discurso de democratização com qualidade (e aqui incluímos acesso, permanência, aprendizagem, infraestrutura material, ambiente favorável ao trabalho e ao ensino, autonomia, democracia, em direção a uma formação humana integral etc.) foi substituído pelo sentido mercantil, de educação como produto e com foco nos resultados.

As principais legislações que regulam a educação nacional, se não incorporaram tais premissas, ao menos omitiram-se quanto à definição do que é entendido por qualidade da educação e/ou do ensino. A Constituição Federal de 1988 trouxe em seu texto a garantia do padrão de qualidade como um dos princípios regentes da educação no País, padrão esse não definido e, portanto, aberto às diversas interpretações existentes. Tal indefinição possibilitou que a LDB definisse qualidade como "a variedade e quantidade mínimas, por aluno, de insumos indispensáveis ao desenvolvimento do processo de ensino-aprendizagem" (Brasil. Lei no 9.394, 1996); na mesma esteira, a LDB não determina quais são os insumos indispensáveis para que a educação ocorra.

No PNE 2014-2024, o significado de qualidade é atrelado ao Índice de Desenvolvimento da Educação Básica (Ideb), apontando para a mensuração da qualidade da educação oferecida nos contextos locais mediante uma fórmula geral que conjuga os resultados dos alunos em avaliações de larga escala e o fluxo escolar. Para o alcance da qualidade exigida, o documento postula que, no ensino fundamental, os anos iniciais devem alcançar a média 6,0 e os anos finais, a média 5,5; para o ensino médio, 5,2 até 2021.

Se considerarmos as médias observadas em 2019, veremos que, para os anos iniciais e finais do ensino fundamental, o Brasil estaria bem próximo de alcançar a desejada qualidade da educação, tendo em vista que as médias obtidas foram 5,9 e 4,9, respectivamente. Porém, ao contrário do que os resultados do Ideb sugerem diante da Meta 7 do PNE, a situação brasileira não parece se aproximar de uma educação de qualidade. Isso ocorre porque a qualidade da educação não pode ser verificada de maneira restrita, ou com base em uma única dimensão, seja ela infraestrutural ou pedagógica. Pensar a qualidade em educação é pensar fatores de diversas origens que intervêm de maneira inequívoca no processo ensinoaprendizagem e na formação humana em última instância, inclusive aqueles de ordem extraescolar - econômica, social, geográfica etc. (Dourado; Oliveira, 2009).

Para a construção da qualidade que almejamos, "é preciso aceitar a escola como ela existe. Isto não significa aceitá-la integralmente, com suas distorções, burocratizada, ritualizada etc. Mas, aceitar, sobretudo, a qualidade da população que entrou na escola, que conquistou a escola" (Beisiegel, 2006, p. 120). Aceitação que 
implica, necessariamente, dar voz aos bárbaros, alargar seus espaços de atuação e fomentar a socialização do poder decisório no interior das instituições escolares.

\section{Colegiados escolares na legislação dos municípios fluminenses}

No período de março de 2018 a março de 2020, procedemos à localização e análise das leis municipais que regulamentam a gestão democrática nas escolas, a fim de compreender como os colegiados têm sido pautados pelos legisladores.

Investigamos e analisamos como se configuram os conselhos escolares, os grêmios estudantis, as associações de apoio à escola, as funções dessas instâncias, quem exerce a presidência delas e o perfil dos participantes, de modo a pensar na dimensão da participação da comunidade escolar para uma educação de qualidade. Lima (2011) defende que participar da decisão nos espaços de colegialidade confere pleno sentido às práticas de governo democrático das escolas, rompendo com encenações participativas, com rituais, processos e métodos formalmente democráticos. Mas, quem define quem participa do regime democrático? Quem é a comunidade escolar, e quem, dessa comunidade, tem o direito à participação na tomada de decisões relativas ao governo da escola enquanto destinatários e proponentes de políticas públicas educacionais?

Buscamos nos endereços eletrônicos oficiais dos 92 municípios do estado prefeituras, câmara de vereadores e secretarias de educação - e localizamos legislações em 38 municípios (Quadro 1). O fato de não localizarmos legislações nos demais municípios pode estar relacionado à não aprovação delas ou, ainda, por não terem sido disponibilizadas em canais oficiais de acesso público.

\section{Quadro 1 - Munícipios do estado do Rio de Janeiro com legislação educacional publicada após 2014}

\begin{tabular}{l|l|l}
\hline Areal & Duque de Caxias & Porto Real \\
Armação de Búzios & Iguaba Grande & Rio das Flores \\
Aperibé & Itaguaí & Rio de Janeiro \\
Barra Mansa & Japeri & Quatis \\
Cabo Frio & Macaé & Queimados \\
Cambuci & Natividade & São Fidélis \\
Campos dos Goytacazes & Niterói & São Francisco do Itabapoana \\
Cantagalo & Nova Friburgo & São José de Ubá \\
Carmo & Nova Iguaçu & São Pedro da Aldeia \\
Casimiro de Abreu & Paraíba do Sul & Saquarema \\
Comendador Levy Gasparian & Paty do Alferes & Seropédica \\
Cordeiro & Petrópolis & Três Rios \\
Duas Barras & Piraí & Valença \\
& & Sumidouro
\end{tabular}

Fonte: Elaboração própria.

Após análise das legislações dos 40 municípios identificados na primeira etapa (Quadro 1), selecionamos os 12 municípios cujos documentos contemplam órgãos colegiados nas escolas e analisamos legislações aprovadas depois da promulgação dos planos municipais de educação e que foram sancionadas após a aprovação do PNE de 2014 (Quadro 2). 


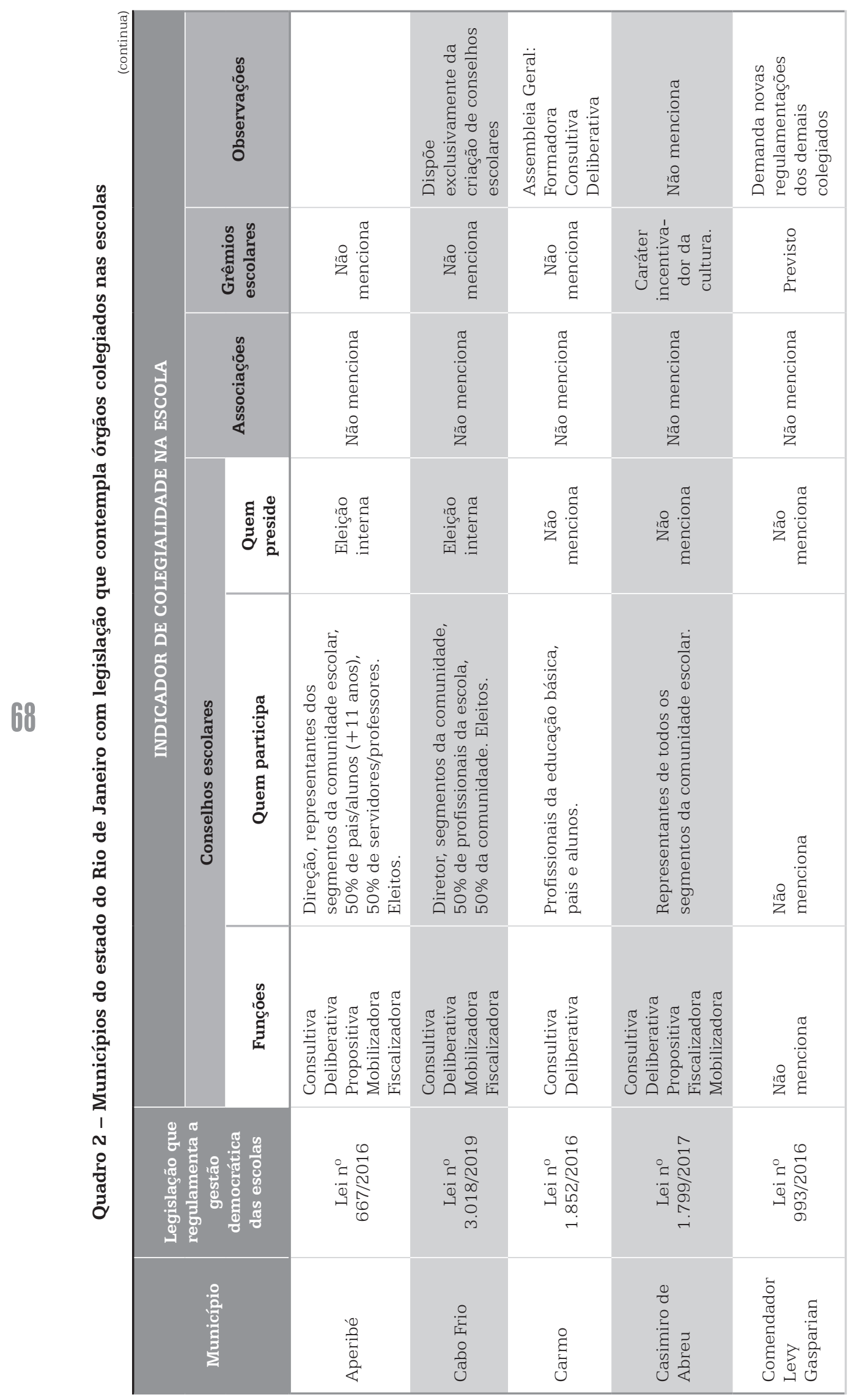




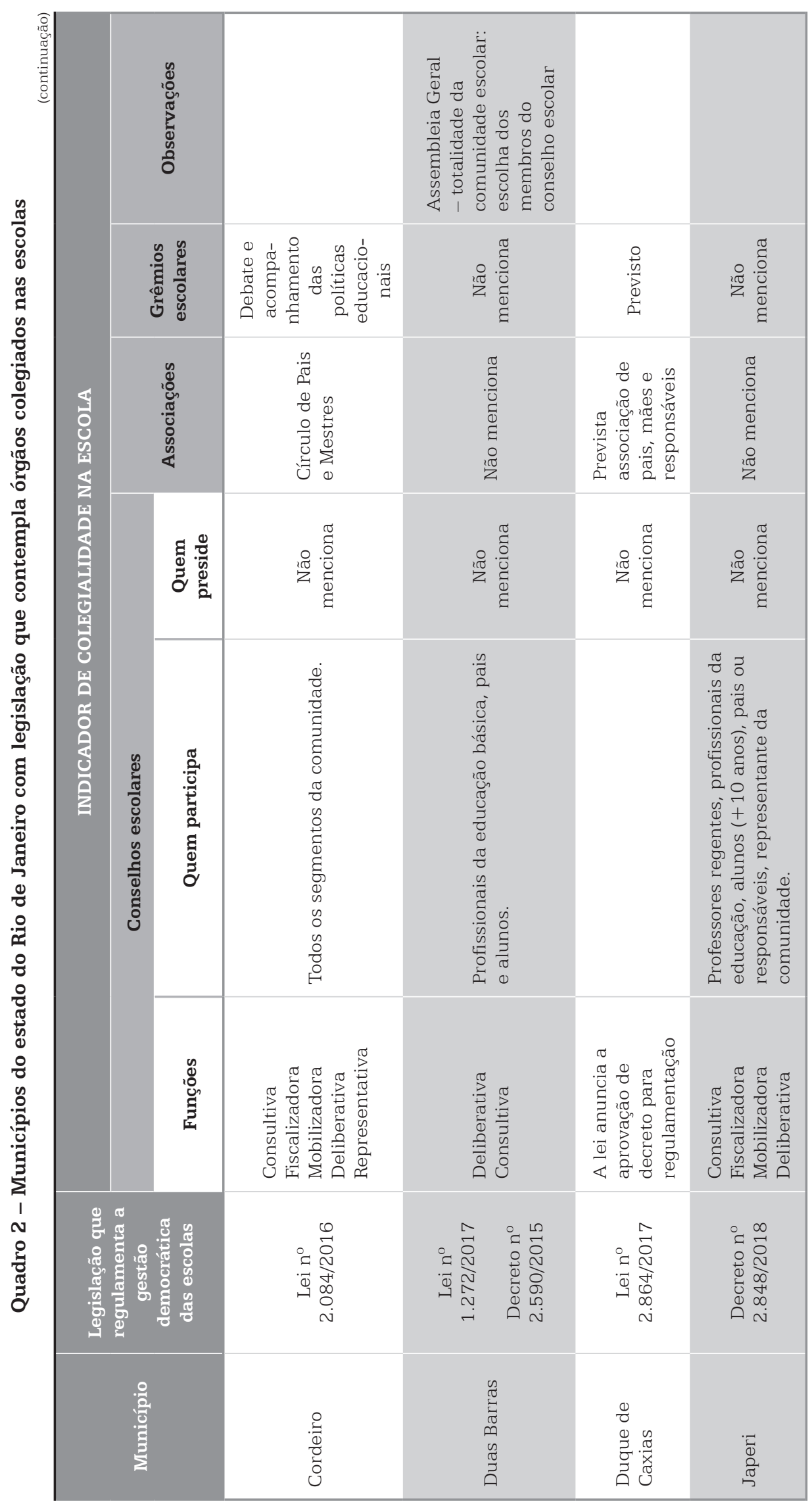

69 


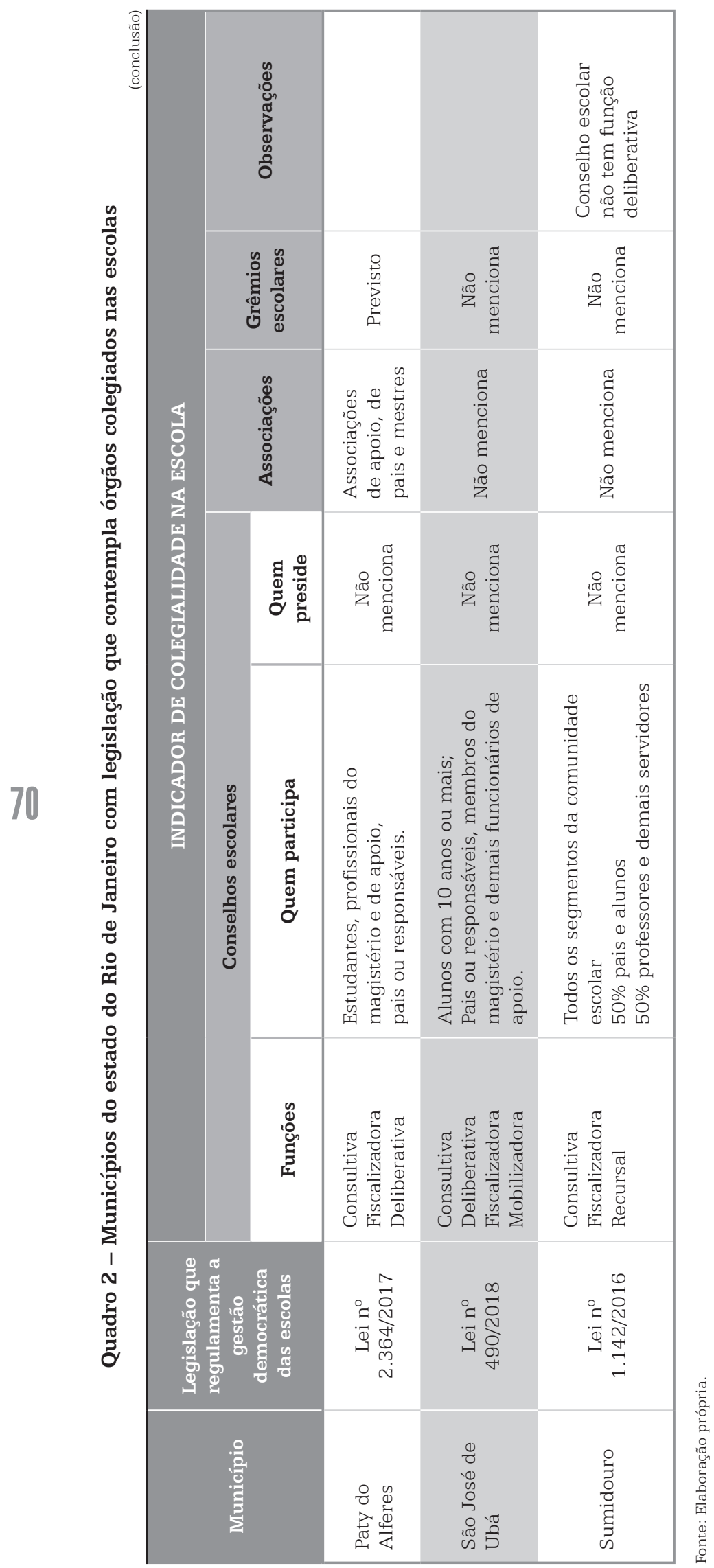

Em Aberto, Brasília, v. 33, n. 109, p. 61-76, set./dez. 2020 


\section{Conselhos escolares}

Acerca das instâncias de colegialidade e participação da comunidade, destacamos os conselhos escolares, que são, na maioria dos municípios investigados, instâncias deliberativas, com exceção de Comendador Levy Gasparian (2017), que, em decreto sobre a indicação de diretores, regulamenta as atribuições deste colegiado no processo consultivo, mas não especifica as funções desse órgão. O município de Sumidouro (2016), em legislação aprovada sobre gestão democrática das escolas, contempla o conselho escolar como instância de colegialidade e participação, mas não atribui função deliberativa ao conselho, desidratando a participação da comunidade escolar nos processos decisórios.

Somente Aperibé e Cabo Frio escolhem o presidente por meio de eleição interna. Essa é uma questão relevante, tendo em vista a cultura instituída de o conselho escolar ser presidido pelo diretor da escola. Esses organismos se apresentam como um importante caminho para a descentralização de ações da/na gestão escolar. No entanto, é comum observar que muitos sistemas de ensino instituíram os colegiados para compor a estrutura administrativa de suas escolas, permanecendo estes na condição de cartórios.

Sobre a participação da comunidade nesse colegiado, observa-se a representação de professores, pais ou responsáveis legais e alunos presente em todos os municípios. Aperibé, Cantagalo e Japeri definiram a idade mínima de participação de alunos, o que pode reduzir as oportunidades para esse segmento. Há certa confusão normativa quanto à opção entre o voto dos servidores públicos (Cantagalo, Comendador Levy Gasparian, Natividade) e o dos profissionais de educação/magistério (Carmo, Duas Barras, São José de Ubá). Restringindo a participação somente aos profissionais do magistério/educação, dependendo do quadro de carreira do município, muitos servidores poderão ser excluídos desse processo, como serventes, porteiros, merendeiras, entre outros.

\section{Associações de pais e mestres}

Acerca das associações de pais e mestres, observamos que ainda não há clareza na tradução dessa política de participação nas escolas. Em Cordeiro mencionase a criação de um círculo de pais e mestres, e em Duque de Caxias e Paty do Alferes, a formação de associações. Por meio de legislações próprias, associações de pais, mestres e funcionários foram instituídas como instâncias executoras dos recursos financeiros da unidade escolar. A perspectiva contemporânea dessas instâncias não é somente de pensá-las como órgãos executores, mas compor esse colegiado de forma que as famílias, especialmente, se apropriem dos discursos que circulam na escola para compreender sua função social e pensar sua gestão e sua relação com o entorno, o bairro, a cidade. A omissão dessas instâncias nos documentos regulamentadores sinaliza importantes elementos para uma baixa escala de democracia e participação na decisão. 


\section{Grêmio estudantil}

O grêmio estudantil, conforme Martins e Dayrell (2013), apresenta uma dimensão educativa muito significativa para os seus membros, e a participação no grêmio envolve posicionamentos e práticas que refletem uma identidade coletiva. Não há menção aos grêmios escolares na legislação em Aperibé, Cabo Frio, Carmo, Duas Barras e Japeri, o que demonstra a exclusão da representação estudantil em um cenário de participação nas escolas, negando as possiblidades de crianças e jovens atuarem na política em um espaço no qual são os destinatários. A participação na decisão é um elemento do processo de constituição desses sujeitos e se inscreve na escola, e o PNE 2014-2024 prevê estimular a constituição de grêmios e associações.

Em dois municípios - Carmo e Duas Barras - estão previstas assembleias gerais com caráter deliberativo. Araújo (2009) destaca que as assembleias escolares são momentos de possibilidade para discussões e compartilhamento de decisões cotidianas, propiciando o diálogo, a negociação e o encaminhamento de soluções dos conflitos. Segundo o autor, a assembleia da escola envolve os representantes dos professores, os alunos e a equipe diretiva e tem como responsabilidade regulamentar as relações interpessoais e a convivência no âmbito dos espaços coletivos, podendo estabelecer o acordo de convivência da escola, um meio de construção democrática das regras de conduta que a escola deve adotar.

\section{Conclusão}

Os resultados iniciais da pesquisa indicam movimentos fragmentados para a regulamentação da gestão democrática, pois observamos certa dificuldade dos municípios em compreendê-la de forma ampliada, o que acaba demandando uma série de regulamentações que, muitas vezes, não dialogam entre si e, em algumas legislações, apesar de suas ementas mencionarem dispor sobre a gestão democrática, regulamentam exclusivamente o processo de seleção de diretores.

Compreendemos a gestão democrática como processo que necessita de permanente acompanhamento e aprofundamento na perspectiva de garantir aos destinatários da escola, suas famílias e comunidade a participação democrática no processo de tomada de decisões relativas ao seu governo. Como afirmado por Lima (2018), a escola pública e democrática nunca esteve garantida no passado, não está garantida no presente e nunca chegará a estar definitivamente garantida no futuro, afinal, a escola democrática não existe a não ser como processo. A participação é balizadora de uma gestão democrática que vincula a comunidade escolar e o poder de decisão. Nesse sentido, algumas questões precisam de aprofundamento.

Os textos políticos são caminhos iniciais e importantes para a pesquisa sobre o cenário da gestão democrática de uma escola com qualidade e equidade e revelam a dinâmica complexa da política educacional municipal. No entanto, a gestão democrática não se garante somente pela existência de normas e legislações que 
regulamentam os espaços coletivos de participação, mas pela forma como esses espaços estão em cena nas escolas.

Compreendendo a qualidade da educação e a gestão democrática enquanto processos permanentemente inacabados e não produtos a serem alcançados, o desafio que se impõe compreende "construir uma sociedade onde os excluídos [...] possam gozar do direito a uma educação radicalmente democrática" (Gentili, 2015, p. 111), na qual haja a participação de todos os sujeitos que da escola fazem parte. A garantia do direito a uma educação de qualidade implica reconhecer que a educação que busca pela equidade precisa reconhecer e respeitar os diferentes tempos de aprendizagem dos estudantes, suas trajetórias pessoais e acadêmicas, considerando o acesso, a permanência, a aprendizagem e a participação na decisão. Para tanto, a gestão democrática representa um potente e fundamental elemento.

\section{Referências bibliográficas}

APERIBÉ (RJ). Lei no 667, de 28 de outubro de 2016. Dispõe sobre a gestão democrática do ensino público de Aperibé-RJ e dá outras providências. Disponível em: <http://aperibe.itcast.com.br/portal/arquivo/1/leis/2016/lei_ municipal_667_-2016.pdf>. Acesso em: 11 fev. 2020.

ARAÚJO, A. C. A gestão democrática e os canais de participação dos estudantes. Revista Retratos da Escola, Brasília, v. 3, n. 4, p. 253-266, jan./jun. 2009.

ARELARO, L. R. G.; JACOMINI, M. A.; CARNEIRO, S. R. G. Limitações da participação e gestão democrática a rede estadual paulista. Educação \& Sociedade, Campinas, v. 37, n. 137, p. 1143-1158, out./dez. 2016.

AZEVEDO, J. M. L. Notas sobre a análise da gestão da educação e da qualidade do ensino no contexto das políticas educativas. Revista Brasileira de Política e Administração da Educação, Goiânia, v. 27, n. 3, 2011.

BAUER, A.; SOUSA, S. Z. Indicadores para avaliação de programas educacionais: desafios metodológicos. Ensaio: Avaliação e Políticas Públicas em Educação, Rio de Janeiro, v. 23, n. 86, p. 259-284, jan./mar. 2015.

BEISIEGEL, C. R. A qualidade do ensino na escola pública. Brasília: Liber Livro, 2006.

BRASIL. Constituição da República Federativa do Brasil. Brasília: Senado, 1988. Disponível em: < httpp://www.planalto.gov.br/ccivil_03/constituicao/ constituicaocompilado.htm>. Acesso em: 22 mar. 2010.

BRASIL. Lei no 9.394, de 20 de dezembro de 1996. Estabelece as Diretrizes e Bases da Educação Nacional. Diário Oficial da União, Brasília, 20 dez. 1996. Texto compilado. Disponível em: < http://www.planalto.gov.br/ccivil_03/leis/ L9394compilado.htm>. Acesso em: 22 mar. 2020. 
BRASIL. Lei no 13.005, de 25 de junho de 2014. Aprova o Plano Nacional de Educação - PNE [...]. Diário Oficial da União, Brasília, 25 jun. 2014. Disponível em: <httpp://www.planalto.gov.br/ccivil_03/_Ato2011-2014/2014/Lei/L13005. htm>. Acesso em: 22 mar. 2020.

BRASIL. Instituto Nacional de Estudos e Pesquisas Educacionais Anísio Teixeira (Inep). A educação no Brasil na década de 90: 1991-2000. Brasília: Inep, 2003.

CABO FRIO (RJ). Lei no 2.902, de 7 de novembro de 2017. Reestrutura o processo de consulta para indicação da equipe de direção das Unidades Escolares. Disponível em: <httpps://cliquediario.com.br/>. Acesso em: 24 mar. 2018.

CARMO (RJ). Lei n¹.852, de 25 de novembro de 2016. Dispõe sobre a instituição da Gestão Democrática na Rede Municipal de Ensino de Carmo. Disponível em: $<$ http://carmorj.itcast.com.br/portal/arquivo/1/leis/2016/18522016.pdf > . Acesso em: 11 fev. 2020.

CASIMIRO DE ABREU (RJ). Lei no 1.799/2017. Dispõe sobre a gestão democrática do ensino público. Disponível em: < https://casimirodeabreu.rj.leg.br/ arquivos/799/Lei\%201799.pdf>. Acesso em: 11 fev. 2020.

CASTRO, A. M. D. A. A qualidade da educação básica e a gestão da escola. In: FRANÇA, M. et al. Política educacional: gestão e qualidade do ensino. Brasília: Liber Livro, 2009.

COMENDADOR LEVY GASPARIAN (RJ). Decreto n ${ }^{\circ}$ 1.621, de 13 de setembro de 2017. Dispõe sobre o estabelecimento de processos consultivos para indicação de diretoras e diretores adjuntos das instituição de ensino.

COMENDADOR LEVY GASPARIAN (RJ). Lei no 933, de 27 de outubro de 2016. Dispõe sobre a gestão democrática do sistema municipal de ensino do município de Comendador Levy Gasparian.

CORDEIRO (RJ). Lei no 2.084, de 22 de novembro de 2016. Dispõe sobre a instituição da gestão democrática no sistema municipal de ensino público. Disponível em: <http://cordeiro.itcast.com.br/portal/arquivo/2/leis/2016/lei_ no_20842016.pdf>. Acesso em: 11 fev. 2020.

DOURADO, L. F.; OLIVEIRA, J. F. A qualidade da educação: perspectivas e desafios. Cadernos Cedes, Campinas, v. 29, n. 78, p. 201-215, 2009.

DUAS BARRAS (RJ). Lei no 1.272, de 30 de outubro de 2017. Dispõe sobre a instituição da gestão democrática no sistema municipal de ensino. Disponível em: <httpp://duasbarras.rj.gov.br/portal>. Acesso em: 12 maio 2018.

DUQUE DE CAXIAS (RJ). Lei no 2.864, de 01 de novembro de 2017. Dispõe sobre a gestão democrática da educação pública do município. Disponível em: < httpp:// duquedecaxias.rj.gov.br/portal/boletim-oficial.html>. Acesso em: 20 jun. 2018. 
ENGUITA, M. F. O discurso da qualidade e a qualidade do discurso. In: GENTILI, P.; SILVA, T. T. Neoliberalismo, qualidade total e educação, 15. ed. Petrópolis: Vozes, 2015.

ESTATÍSTICAS da educação básica no Brasil. [s.l.: s.n.], 1996. 25 p. Consta em nota de rodapé na primeira página: Extraído do Relatório para a Conferência Internacional de Educação em Genebra, 1996. Disponível em: < http://portal. inep.gov.br/documents/186968/484154/Estat\%C3\%ADsticas + da+educa\% C3\%A7\%C3\%A3o+b\%C3\%A1 sica + no+Brasil/e2826e0e-9884-423c-a2e4658640ddff90?version=1.1>. Acesso em: 30 abr. 2020.

GENTILI, P. Neoliberalismo e educação: manual do usuário. In: GENTILI, P.; SILVA, T. T. (Orgs.). Escola S. A.: quem ganha e quem perde no mercado educacional no neoliberalismo. Brasília: CNTE, 1996. p. 9-49.

GENTILI, P. O discurso da "qualidade" como nova retórica conservadora no campo educacional. In: GENTILI, P.; SILVA; T. T. Neoliberalismo, qualidade total e educação. 15. ed. Petrópolis: Vozes, 2015.

HOBSBAWM, E. Era dos extremos: o breve século XX - 1914-1989. São Paulo: Companhia da Letras, 1995.

JAPERI (RJ). Decreto n 2.848, de 7 de novembro de 2018. Diário Oficial do Município de Japeri, n. 4.279, 14 nov. 2018.

LIMA, L. C. Administração escolar: estudos. Porto, Portugal: Porto Editora, 2011.

LIMA, L. C. A gestão democrática das escolas como referencial político, educativo e simbólico: entrevista com o professor Licínio Lima. Entrevistado por Daniela Patti do Amaral. Movimento Revista de Educação, Niterói, v. 5, n. 8, p. 244-256, jan./jun. 2018.

MARTINS, F. A. S.; DAYRELL, J. T. Juventude e participação: o grêmio estudantil como espaço educativo. Educação \& Realidade, Porto Alegre, v. 38, n. 4, p. 12671282, out./dez. 2013.

NAJJAR, J. A disputa pela qualidade da escola: uma análise do Programa Nova Escola do Estado do Rio de Janeiro. Niterói, RJ: EDUFF, 2015.

OLIVEIRA, R. P.; ARAÚJO, G. C. Qualidade do ensino: uma nova dimensão da luta pelo direito à educação. Revista Brasileira de Educação, Rio de Janeiro, n. 28, p. 5-23, 2005. Disponível em: <https://www.scielo.br/scielo.php?pid=s1413$24782005000100002 \&$ script $=$ sci_abstract\&tlng=pt>. Acesso em: 26 nov. 2020.

SÃO JOSÉ DE UBÁ (RJ). Lei no 490, de 20 de março de 2018. Dispõe sobre a criação dos conselhos escolares nas escolas públicas municipais de São José de Ubá.

PATY DO ALFERES (RJ). Lei no 2.366, de 24 de outubro de 2017. Dispõe sobre a gestão democrática do sistema municipal de ensino do município de 
Paty do Alferes. Disponível em: <http://patydoalferes.rj.gov.br/wp-content/ uploads/2010/09/D.O.-2681-24-10-2017-ok.pdf>. Acesso em: 11 fev. 2020.

SOUZA, A. R. Explorando e construindo um conceito de gestão escolar democrática. Educação em Revista, Belo Horizonte, v. 25, n. 3, p. 123-140, dez. 2009.

SUMIDOURO (RJ). Lei no 1.142, de 15 de junho de 2016. Dispõe sobre a gestão democrática do ensino público municipal de Sumidouro.

Karine Vichiett Morgan, doutora em Educação pela Universidade Federal Fluminense (UFF), é professora adjunta nas Faculdades Integradas Maria Thereza (Famath). Pesquisadora do Núcleo de Estudos e Pesquisas em Gestão e Políticas Públicas em Educação (Nugeppe). Especialista em Administração e Supervisão Educacional. Vice Coordenadora Regional Sudeste da Associação Nacional pela Formação dos Profissionais da Educação (Anfope).

morgan.uff@gmail.com

Daniela Patti do Amaral, doutora em Educação pela Universidade Federal do Rio de Janeiro (UFRJ), com pós-doutorado em Administração Pública pela Escola Brasileira de Administração Pública e de Empresas (Ebape) da FGV-RJ e pósdoutorado em Ciências da Educação pela Universidade do Minho, Portugal, é professora da Faculdade de Educação da Universidade Federal do Rio de Janeiro (UFRJ) e docente do Programa de Pós-Graduação em Educação dessa universidade, orientando dissertações e teses na linha de Políticas e Instituições Escolares. Atua como diretora da seção estadual (Rio de Janeiro) da Associação Nacional de Política e Administração da Educação (Anpae). É coordenadora do Grupo de Estudos e Pesquisas dos Sistemas Educacionais (Gesed), cadastrado no CNPq.

danielapatti.ufrj@gmail.com

Recebido em $1^{\circ}$ de julho de 2020

Aprovado em 16 de outubro de 2020 